\title{
TRADUCCIÓN
}

\section{Señorita Elefanta Salvaje}

\section{Miss Elephant Savage}

\author{
ZHANG CHU \\ Traducción del chino y nota de \\ LILJANA ARSOVSKA*
}

\section{E1 autor}

Zhang Chu nació en 1974 en Tangshan, provincia de Hebei. Este joven escritor, miembro de la Asociación de Escritores de China, ha publicado muchas novelas cortas y cuentos en revistas literarias de gran prestigio, como Shoubuo, Renmin wenxue y Shiyue, entre otras. En su antología Yingtao (Cerezas) destacan los siguientes cuentos y novelas cortas: "Qi gen kongque yumao" (Las siete plumas del pavo real), "Ye shi zenme heixialiade" (Cómo la noche se torna negra), "Yexiang xiaojie" (Señorita Elefanta Salvaje), "Zai yunluo" (En las nubes) y "Fangapo de huochai” (La fosforera de Van Gogh), entre otros. Su antología de ensayos Mimi buban zijide mingzi (Gritar en secreto tu nombre) ha recibido excelentes críticas del gremio de escritores de su país. Su trabajo ha sido reconocido con varios premios literarios importantes, como el $\mathrm{Lu}$ Xun de literatura, el Yu Dafu, el de Renmin wenxue a la novela corta, el Águila Roja de la Asociación de Escritores de China, el de Literatura de Bei-

Recepción: 8 de agosto de 2017. / Aceptación: 31 de agosto de 2017.

*El Colegio de México, liljana@colmex.mx 
jing, el premio al mejor escritor joven de la revista literaria Shiyue, y el Cien Flores de la revista Xiaoshuo yuebao. También recibió el título de "Joven escritor del año" por parte de Renmin wenxue y Nanfang wentan.

\section{Señorita Elefanta Salvaje}

Cuando empecé a traducir esta novela, que me cautivó desde la primera lectura, no sabía quién era su autor. Las primeras páginas e incluso las primeras líneas me hicieron pensar que se trataba, seguramente, de una escritora que conocía bien el alma de las mujeres, ya que la voz narrativa describe con gran sensibilidad el dolor de padecer cáncer de mama y, al mismo tiempo, ser engañada por su pareja. Y estos pesares físicos y emocionales de la narradora no le impiden dar cuenta, con lujo de detalles, de la historia de la señorita Elefanta, la afanadora del hospital.

Elefanta Salvaje, una mujer gorda ante un sinnúmero de ojos que la miran sin verla, asea todos los días el hospital donde la narradora y sus camaradas libran la batalla en contra del cáncer, la plaga de nuestro tiempo. Como el sueldo no alcanza, Elefanta junta a escondidas las botellas vacías de plástico para venderlas a las empresas de reciclaje. Las pacientes del área de cáncer de mama la desprecian, la sociedad entera la desprecia y ella es consciente de ese repudio, pero no es algo que la perturbe.

Desprecian su gordura, su falta de baño diario, su ridículo atuendo, sus piernas anchas que se arrastran al barrer, su necesidad económica que la obliga a juntar botellas incluso entre la mierda de la basura. Ella, sin embargo, no escatima fuerzas ni voluntad para alegrar la vida de las enfermas. Lo hace con una palabra, con una broma o con una invitación a un espectáculo nocturno donde la señorita Elefanta es la estrella de la noche.

Elefanta rompe el esquema de la muchacha joven, esbelta y sensual que se desliza por un tubo ante la mirada libidinosa de los hombres. Su espectáculo de acrobacia, grotesco e incluso vulgar, arranca risas y admiración a sus espectado- 
res ávidos de diversión, y ella, por su parte, logra con esa actividad completar sus ingresos para mantener a su hijo con parálisis cerebral.

El lector de esta novela corta tiene la ardua tarea de decidir cuál de las desgracias narradas es la más grande. Para mi gran sorpresa, es un hombre el autor de esta excelsa obra. 


\section{Señorita Elefanta Salvaje}

Pensé en divorciarme de Ningmeng. Si no me equivoco, ésta era la segunda vez.

- ¿Has estado emberrinchada durante días y aún no te contentas? - me preguntó Ningmeng mientras me frotaba lentamente el hombro-. No seas así, escúchame.

Siempre era él quien me escuchaba. Tenía mucha fuerza en sus grandes y muy hábiles manos: sabía cocinar sopa coreana de soya, pescar calamares a la orilla del mar, reparar motocicletas importadas, doblar grullas de papel, conectar cables quemados, ensamblar libreros extraños comprados en Taobao; ${ }^{1}$ también sabía tallar budas en una semilla de olivo.

-No me toques - le dije.

Dejó de hablar y, con la cabeza agachada, comenzó a jugar con la semilla de cereza donde había tallado dieciocho arbats.

Caminé silenciosamente hacia la ventana. En el estacionamiento metían a un anciano dentro de una ambulancia camino a la clínica; varias mujeres lloraban y se empujaban entre sí mientras arrastraban a un hombre envuelto en sábanas blancas hacia una camioneta roja. Eran todos tan pequeños e insignificantes... parecían granitos de arena que el viento caliente del desierto arrastraba hacia el vacío. Mucha gente iba y venía todos los días y todos sabían que ese sitio era el portal de la muerte.

- ¿Qué quieres para almorzar? - preguntó mientras me abrazaba por detrás-. ¿Qué tal una paloma guisada en caldo?

Me di la vuelta y lo miré. Durante tantos años, despierto o dormido, en el día y en las noches, había mirado innumerables veces al hombre con el cual compartía el lecho. Su nariz respingada como cuando lo conocí; los pelos recortados, limpios y ordenados; las comisuras de los labios ligeramente levantadas y, un poco más arriba, una verruga que parecía excremento de mosca. Excepto por las dos arrugas delgadas en la esquina del ojo, él estaba igual que antes.

${ }^{1}$ Compañía china de compras por Internet. 
-Es sólo una charla casual... -murmuró-. ¿Qué te pasa? Miré fijamente sus pupilas; jamás le había dicho que, cuando mentía, se le hinchaban las pupilas.

-Ya, mujer -insistió con voz ronca-; están de vuelta.

Me sacudí la enorme mano que había intentado trepar por mi hombro. No tenía ganas de hablar. Hacía tiempo que, tumbada en la cama del hospital, con los ojos parpadeando como luces intermitentes, miraba al techo, donde sólo había unas cuantas grietas retorcidas. A veces, vagamente entreveía la sombra de un hombre legendario, o a un bebé acurrucado en el seno de la virgen María que buscaba con labios ávidos los pechos jugosos.

Volvieron del paseo.

Eran mis compañeras de cuarto: la hermana An, la Concubina China y Cuicui, así como su hombre de pies apestosos.

An nunca hablaba; acurrucada en la cama solía escuchar cuentos en la radio. La Concubina China encendía la computadora, se colocaba los auriculares en los oídos y se sentaba a ver Las emperatrices del palacio. Comentó que había visto tres veces esa serie. Nos había pedido que olvidáramos su nombre, Liu Shufang, y la llamáramos Concubina China. Mientras Pies Apestosos le daba masaje a Cuicui, ella ocasionalmente emitía maullidos de gato montés.

- Hace tiempo que no viene tu hijo - le dijo la Concubina a An-. Es hora de hablarle por teléfono.

-Está ocupado - respondió An pausadamente-. Rodar por Beijing es como andar sobre el filo de la navaja con las nalgas desnudas.

La Concubina suspiró, se volvió y me preguntó:

- Hermosura, tienes la cara más estirada que una esponja, ¿qué tienes? Cuéntale a tu hermana mayor.

Al igual que todas, la odiaba

- Ya es mediodía, y usted aún no ha saludado al palacio, los cortesanos pensarán que no le importa su casa -le dije. 
La Concubina rio. Con su cara abultada y su pequeña boca fruncida se parecía muchísimo al pajarraco enojado de los juegos de Nintendo.

-No has perdido el pelo - afirmó-, pero con dos quimioterapias más estarás pelona.

La peluca en su cabeza regordeta parecía un sombrero de paja mal tejida. Había encajado una horquilla brillante en el sombrero de paja, y dijo que su hermano se la había comprado en el bazar de Urumqi. ${ }^{2}$

Las cuatro nos operamos en las mismas fechas, y para la quimioterapia nos acomodaron en la misma habitación. Después de seis días en el hospital, regresábamos veinte días a casa y luego nos internábamos de nuevo...

Estábamos predestinadas a estar juntas. Ésta era la cuarta cita y ninguna de nosotras se derrumbaba. Pensé que eran como mis parientes pobres, que me enfermaban pero que no podía evitar.

Cuicui se quejó del fuerte masaje de su marido, Pies Apestosos. La Concubina aventuró:

-Pies Apestosos te quiere estrangular para poder desposar a Elefanta Salvaje, que aún es virgen.

Cuicui, con voz infantil, susurró:

-Concubina, baja la voz, ya viene...

Elefanta Salvaje, pas, pas, pas, realmente venía. Oímos el sonido de sus pasos, que incluso en el pasillo silencioso que llevaba a nuestra habitación, eran ruidosos. Casi podíamos ver sus dos piernas gordas, duras y lentas, su cintura de tarro y un montón de grasa meneándose al ritmo de sus pasos. Para calmar sus palpitaciones, soltaba la escoba, el recogedor y el trapeador, y descansaba unos instantes apoyada en la pared del estrecho pasillo, y luego, con sus zapatos talla cuarenta y cuatro, comenzaba a pulir el piso hasta sacarle gemidos cristalinos. A decir verdad, nunca había visto a una mujer tan gorda. Pensé que con un solo brazo podía levantarme y lanzarme a la luna.

-Denme todas sus botellas vacías - dijo An-, pero primero apachúrrenlas.

Perpleja, pregunté:

${ }^{2}$ Capital de la región autónoma de Xinjiang. 
-Ningmeng, ¿por qué no pones atención?

Él jugaba con su móvil. Sonrió y se puso a sacar las botellas de plástico vacías, escondidas debajo de la cama, las aplastó y, sonriendo, me preguntó:

- ¿Viene Elefanta Salvaje?

Elefanta Salvaje era la afanadora del hospital. Al parecer llevaba ya muchos años trabajando ahí; los doctores viejos y los doctores jóvenes, las enfermeras, los trabajadores, incluso los enfermos viejos con la cara rabiosa y los labios caídos, todos la conocían. Siempre vestía una blusa azul ajustada a la altura de sus pechos frondosos y caminaba como perezoso elefante de circo. Yo desconocía el origen de su apodo. ¿Por qué le llamaban Elefanta Salvaje y no simplemente Elefanta o Elefanta Doméstica? En mi imaginación, los elefantes eran animales torpes y apacibles, como todos los herbívoros, y sus ojos arrugados siempre me recordaban a los pacientes con tuberculosis, postrados eternamente en cama. Ella, además de barrer, fregar pisos y limpiar retretes, recogía botellas de plástico vacías. Recoger botellas estaba prohibido en el hospital, pero ella, siempre misteriosamente y a escondidas, preguntaba: " $¿$ Tienen botellas de agua mineral?... Botellas de agua mineral", y sus ojos grises brillaban alegremente cuando pronunciaba esas cuatro palabras. Más tarde, ya familiarizados, ni siquiera tenía que hablar: sacaba la lengua, sacudía los ojos, estiraba el pulgar de la mano derecha y el dedo medio, se meneaba y nosotras rápidamente le entregábamos las botellas vacías. Como no teníamos nada que hacer, An nos pidió que aplastáramos las botellas para evitarnos el ruido de los pies gigantes de Elefanta Salvaje.

-Ustedes son buena gente - dijo Elefanta, que había comprado una sandía y nos había obligado a comer cuatro o cinco rebanadas a cada una-; después dejaré la bolsa aquí en su cuarto.

Escondía las botellas vacías en bolsas para orinar. Sin duda libraba una guerra de guerrillas; hoy escondía la bolsa en el baño de los hombres, mañana en el de las mujeres, y otras veces también deslizaba a escondidas el bulto que emitía un fuerte 
olor a fertilizante en el armario de los médicos. Ahora las cosas habían mejorado: dejaba la bolsa debajo de la cama de An y, en las noches, antes de irse a su casa, se asomaba por el marco de la puerta y susurraba: “iNingmeng, Ningmeng!”.

Ningmeng, después de salir del asombro, inmediatamente, a velocidad de carrera de cien metros planos, bajaba en el elevador hasta la planta baja, esquivaba la sala de correo y llegaba al estacionamiento. Elefanta Salvaje, ya mudada de ropa para irse a su casa, aventaba el bulto por la ventana. Esta mujer debería de practicar tiro de disco, pensé, pues la bolsa, después de vagar unos instantes en el aire, caía directamente a los pies de Ningmeng. Frotándose las grandes manos como abanicos, se despedía de nosotras diciendo: "Adiós, guapas".

Usualmente, después de seis días de quimioterapia regresábamos a casa. Pensé que los pacientes que tomaban nuestro cuarto después de nosotras probablemente no eran tan amables ni pacientes con Elefanta Salvaje, ni ella con ellos quizá. Después de hacer su trabajo, iba a nuestro cuarto a charlar. Siempre estaba apoyada en el marco de la puerta, y si la enfermera llegaba a medirnos la temperatura, tenía que pasar por debajo de su axila. Le gustaba charlar con An, que no se parecía para nada a la Concubina China, quien siempre se mofaba de ella.

- ¿Por qué no te dedicas a la halterofilia? Es una lástima desperdiciar ese físico - le dijo una vez la Concubina.

-De niña era yo muy flaca -contestó Elefanta Salvaje ruborizada y lamiéndose los labios-. Yo quería ser gimnasta. En realidad, soñaba con hacer un salto de lobo y una voltereta en la barra de equilibrio.

La Concubina, con la cara estirada, replicó:

-Por suerte no practicaste gimnasia. Un salto tuyo y adiós a la barra. Además de darte cero puntos, el árbitro te haría pagar por el equipo.

-Tienes razón - admitió Elefanta Salvaje un poco herida-, los pobres como yo ¿a qué pueden aspirar?

-A los pobres no les falta voluntad porque sean pobres -arguyó An-; estás un poco gordita, pero tienes ojos grandes y párpado doble y eres hermosa. ¿Por qué no te pones un vestido decente? Siempre desprendes un olor rancio. 
-Ay, no, no me digas eso — se defendió Elefanta Salvaje-. ¿Cómo que siempre huelo a rancio? Yo amo la limpieza y me baño una vez al mes.

De pronto recordé que en la tienda había visto una falda para embarazadas y se la compré.

- ¡Oh, Dios mío!, ¡qué regalo! —exclamó mientras con sus ojos de párpados gruesos se quedaba mirando la falda floreada y, después, ansiosa, preguntó:

-Me va a... ¿Me quedará?

-Claro que sí - le aseguré-. Lo había pedido una embarazada que a la mera hora abortó.

-Muy bien, me gusta mucho este color, racimos de magnolias muy hermosas.

-No, no son magnolias, son tulipanes -le aclaré.

Ella sonrió.

-Me gustan los tulipanes. Mi flor favorita en el mundo son los tulipanes.

Nos quedamos pasmadas el día que llegó a trabajar con esa falda de maternidad llena de tulipanes. Se hizo un nuevo peinado; su pelo grueso como tallarines de sopa instantánea caía sobre sus hombros, traía los labios pintados de rojo escarlata y de su cuello colgaba un collar de conchas; incluso las uñas de sus pies estaban pintadas de rojo púrpura.

- ¿Quién eres? -le preguntó la Concubina-. Miss Mundo llegó al hospital para realizar labores altruistas...

Elefanta Salvaje rio tanto que hasta su muela de oro salió a relucir:

- ¿Realmente estoy bonita?

- Por supuesto - recalcó la Concubina-. Si hubieras nacido en la dinastía Tang, ¡Yang Huayi ${ }^{3}$ sería insignificante a tu lado!

-Sólo que está un poco corto - dijo An mirándola de arriba hacia abajo-; se vería mejor con un par de medias.

-Las compraré al mediodía -agregó contenta-. El centro comercial Hualian tiene ofertas en estos días.

${ }^{3}$ Una de las cuatro beldades de China. 
No esperaba que se acercara y me abrazara. Tenía un fuerte olor a agua del inodoro.

-Muchas gracias - dijo.

Le eché un vistazo torpemente y añadió:

-Cuando tenga dinero, te compraré un bistec.

Ese día, los doctores, las enfermeras y los pacientes la miraron pasar como se mira a un monstruo que arrastra sus dos piernas pesadas moviendo el trapeador de un lado a otro a lo largo del pasillo. Veía conocidos y los saludaba sonoramente; alguien la miraba de reojo y ella, ni tarda ni perezosa, preguntaba:

$-i$ Crees que es hermoso mi vestido? Mi hermana me lo compró. ¿Sabes qué flores son? ¡Tulipanes!

Las personas respondían cualquier cosa sin ganas cuando ella, con su boquita a punto de escupir un gargajo, preguntaba:

- ¿Tienen botellas vacías? ¡Guárdenmelas!

Justo cuando recogía botellas ocurrió el incidente.

Contaron que un funcionario llegó al hospital para inspeccionar la higiene. Cuando él y sus acompañantes fueron al baño, encontraron dos piernas colgando de un enorme tambo de basura. El director del hospital, que caminaba al frente del grupo, aturdido, se quedó mirando fijamente las gruesas piernas y el vestido atado a unas caderas, y durante un largo instante no fue capaz de pronunciar ni una palabra. Golpeó suavemente la cintura que se sumergía en el tambo, y fue entonces cuando Elefanta Salvaje salió lentamente de él. De sus cabellos que parecían fideos de sopa instantánea colgaba una hoja de lechuga. Sosteniendo en cada mano una botella vacía y sonriendo, preguntó:

- ¿Por qué me acaricia el trasero?

El director replicó desconcertado:

- ¡Asustas, mujer!

Elefanta Salvaje contestó indignada mientras miraba las botellas:

-¿Qué paciente es tan desalmado? Arrojó una botella al basurero en medio de pura mierda.

El director retrocedió unos pasos, se tapó la nariz apretando con fuerza y preguntó:

-Claro que las tiran al bote de la basura, ¿o quieres que las arrojen por la ventana? 
Elefanta Salvaje se golpeó el pecho y dijo jadeando:

-Claro, aquí estoy, ¿o no? Soy la reina de la basura.

El director inquirió:

- ¿Para qué quieres las botellas?

Entonces la que se asustó fue Elefanta Salvaje. Limpió las botellas con papel higiénico y lentamente respondió:

-Dinero. Un centavo por botella, veinte botellas son dos yuanes, con los que compro cinco naranjas en el supermercado.

Cuando terminó de hablar se arrepintió, pues detrás del pelón con gafas al que se había dirigido estaba la jefa de enfermeras. Por supuesto que en el momento no entendió la gravedad del asunto. Pero cuando media hora más tarde recibió un aviso de despido, todo le quedó muy claro. Se desplomó en la esquina del pasillo y no dejó de temblar. Los pacientes la miraban curiosos al pasar a su lado, mientras ella, bañada en lágrimas, se esforzaba en sonreír. El polvo de su cara se fundía con aquella sonrisa divertida y añeja. Era como un elefante de circo, viejo y enfermo, escondido en su jaula comiendo pasto; sólo que ese elefante traía puesto un vestido de maternidad repleto de tulipanes.

Durante mucho tiempo no le presté atención a Ningmeng. Pero tenía muchos motivos para querer el divorcio. En mis últimas sesiones de quimioterapia, mi madre había sido quien me había acompañado. Al regresar a casa uno de esos días, preparé algunos platillos suculentos y abrí una botella de vino que unos amigos nos habían traído de Australia. Se lo bebió todo y luego se durmió en la silla. Su móvil estaba en la mesa. Siempre me arrepentiré de haberlo mirado. En la pantalla vi el registro de su chat obsceno con una mujer. Mi rostro se encendió y mi corazón empezó a palpitar aceleradamente. Lo que me sacó de quicio fue que la mujer conocía a nuestra familia, nuestra dirección, el nombre de nuestro hijo, mi unidad de trabajo... También sabía que, en otros tiempos, cuando Ningmeng me cortejaba, había pasado toda una noche en la puerta de mi casa con un ramo de rosas en las manos. Según Ningmeng, él 
jamás había visto a esa mujer; la había encontrado por casualidad en internet.

- Me sentía vacío, tú no estabas en casa, y en el ocio me puse a jugar.

- ¿Está lejos el fin del mundo?

-Está lejos.

-Lárgate entonces al fin del mundo.

Obediente, se fue a dormir al estudio.

Lloré toda esa noche. Había sido diagnosticada con cáncer de mama; las dos mamas me fueron extirpadas por completo. A decir verdad, jamás pensé que fuera tan serio. Entre recoger los resultados de la biopsia y estar tendida en la plancha del quirófano, sólo pasaron tres horas. El tío de Ningmeng era el decano del hospital. No había cama disponible y el cirujano principal estaba realizando prácticas en el hospital Unión de Beijing. Pero una llamada del tío hizo regresar al cirujano. Mientras sostenía el frío bisturí con la mano, pude sentir su respiración agitada.

Y ahora tuve que echar mano de Ningmeng:

- ¿Tu tío no está fuera de la ciudad?

-No - contestó sorprendido.

-Llámalo y pídele que restituya a Elefanta Salvaje.

- ¡No hay problema!

Lo vi salir del pabellón y llamar. Hemos estado separados por mucho tiempo. Había pensado cuidadosamente en el significado de los pechos para las mujeres y para los hombres, $\mathrm{y}$ por más que quería entender, no lo lograba, hasta que un día, accidentalmente, leí en una revista vieja en el hospital un poema escrito por un chileno llamado Pablo Neruda:

Se parecen tus senos a los caracoles blancos.

$\mathrm{Ha}$ venido a dormirse en tu vientre una mariposa de sombra.

Ah silenciosa!

Y entonces supe que mis pechos habían sido silenciados y yo también quedé en silencio. También supe que Ningmeng no sólo había perdido sus caracoles blancos.

-Le dije al tío, no hay problema -me tranquilizó Ningmeng mientras sonreía-. Volveremos a ver a Elefanta Salvaje de nuevo por aquí. 
Efectivamente, volvimos a ver a Elefanta Salvaje, pero ella ya no se atrevió a recoger botellas vacías. Después de la limpieza, se deslizaba como siempre a nuestra habitación y, recargada en la pared, se ponía a charlar. La Concubina aún disfrutaba burlarse de ella.

-Esta vez sólo fue un susto.

- ¿Cómo puedo ser tan estúpida? -se lamentó golpeándose la boca-. La jefa de enfermeras anteayer me advirtió que vendrían a inspeccionar la limpieza. Pero yo veo una botella en la basura y simplemente no me puedo resistir.

- ¿La sacarás incluso si está llena de mierda?

-A tus ojos es mierda, a mis ojos es dinero.

-Tienes buena suerte, los espíritus te ayudan.

- ¿En serio crees eso? - preguntó Elefanta Salvaje-. Me morí del susto. Si realmente me hubieran despedido, ¿dónde podría encontrar un trabajo tan bueno? Las gordas no tenemos la suerte de los gordos.

-Sí, mujer - dijo la Concubina tocándose la horquilla de plata en su peluca-. ¿Acaso no le darás las gracias a tu salvadora?

$-i$ Mi salvadora?

-La más guapa entre nosotras intercedió por ti y por eso no te despidieron.

Así fue como la Elefanta Salvaje me abrazó por segunda vez. Yo no la esquivé y me hundí en su abrazo exagerado. Sus pechos grandes y blandos estrujaron mi pecho y mis ojos se humedecieron.

-Eres una buena persona -me susurró al oído-. ¿Por qué a la gente buena siempre le pasan cosas malas?

Desde entonces, ella venía más frecuentemente a nuestra habitación. Claro que pocas veces llegaba con las manos vacías. Pronto conocimos los rábanos silvestres encurtidos, los hilos de calamar ultra picante, los elotes hervidos y toda clase de comidas que de otra manera no habríamos probado nunca. Por ejemplo, una vez trajo una caja de plástico con algo rojo en forma de pezón. Los palillos en nuestras manos bailaban, pero nadie se atrevía a probar primero. La Concubina no aguantó:

- ¿Qué es esto?

Elefanta Salvaje señaló orgullosamente: 
-Es un secreto. Lo sabrás cuando lo pruebes.

Nos dio más miedo probar aquello. Elefanta Salvaje tomó mis palillos y me metió a la fuerza un pedazo a la boca:

-Come, éste es pezón de cerda, lo compré apenas esta mañana en el mercado Loto. La medicina china dice que "debes comer lo que te falta".

Todas nos quedamos en silencio. Finalmente, An dijo:

-Nuestra Elefanta Salvaje nos consiente de esta manera y nosotras la desairamos, ¿por qué? Oh, esto huele bien. ¡Anden, coman!

La Concubina me miró, se acercó un pedazo a la boca y comenzó a masticar. An le dijo:

-Come despacio. Mírate, no sabes ni sentarte ni comer.

Todos sabíamos que An había estado de mal humor últimamente. Su hijo no había venido al hospital hacía dos meses y raras veces la llamaba por teléfono.

El cabello se le cayó y nuestra habitación comenzó a parecer un convento.

El hijo de An finalmente apareció. Era un tipo tranquilo que apenas sonreía, delgado y levemente jorobado. Cuando vino el doctor a la habitación, él asintió con la cabeza y dijo:

- Gracias, doctor, gracias por cuidar a mi madre.

Cuando vino la enfermera, él asintió con la cabeza y dijo: - Gracias, enfermera, gracias por cuidar a mi madre. dijo:

Cuando vino Elefanta Salvaje, él asintió con la cabeza y

- Gracias, gracias por cuidar a mi madre.

- ¿Quién eres? - preguntó Elefanta Salvaje.

Él entornó los ojos y aclaró:

-Usted ha trabajado duro, yo soy An Changhe.

An Changhe era muy presto. En unos instantes limpió la mesa de su madre y después intentó limpiar las nuestras. No lo dejamos; él nos miró con vergüenza, por lo que tuvimos que dejarlo usar gasa blanca para limpiar la mesa vieja y descarapelada. Cuando terminó, miró a su madre, que estiró la cara sin decir 
ni una palabra. Él, entonces, comenzó a limpiar las ventanas. Estaba segura de que aquellos vidrios no habían sido limpiados desde que el hospital fue construido. Trabajó durante una hora hasta dejar las ventanas relucientes. Después apoyó sus manos en sus caderas, miró por la ventana y anunció:

- Mamá, mañana voy a ir a Shenzhen por negocios, en el avión de las diez.

-Ve si tienes algo que hacer - contestó An- No retrases tu trabajo; además, ahora eres subgerente.

Volvió la cabeza y, sin hablar, miró a An.

Por la tarde dijo que iba a salir a comprar agua mineral y se tardó en volver. An estaba preocupada. La Concubina la consoló:

-Ay, mujer, toda la vida preocupándote, a sus veintitantos ya es un hombre hecho y derecho, ¿qué le puede pasar?

Pero An aclaró:

-Ustedes no saben, es un niño tímido; a los ocho años aún lloraba cuando veía una mantis, sin duda se parece al cobarde de su padre.

La Concubina insistió:

-Por más inútil que sea, ya vive en la capital, es gerente de una empresa y viaja por negocios en avión. ¿Qué más quieres, mujer?

An apenas entonces esbozó una leve sonrisa:

-Eso sí, siempre fue buen estudiante, fue campeón de ciencias en nuestra ciudad.

An Changhe regresó con diez botellas de agua mineral en el regazo, limpias y acomodadas en una pirámide impecable donde todas estaban enganchadas una a la otra. Su camisa blanca, completamente mojada, delineaba su escápula salida:

-Quería comprar un poco de agua fría, pero en la planta baja no había, así que fui a la tienda, aunque costaba un centavo más que en el supermercado. No pensé que el supermercado estuviera tan lejos - dijo sonriendo tímidamente-; afortunadamente tengo pies voladores.

De pronto, estiró una mano para secarse el sudor y, ¡uf!, todas las botellas cayeron al suelo y unas cuantas incluso salieron de la habitación. 
- ¿Qué tonto! ¡Qué inútil! - gruñó An de repente-. ¡Cómo pude parir una cosa tan inútil! Te ahorraste un yuan al comprar el agua en el mercado. Por más rápido que corras, ¿ipuedes ganarle a un coche? ¿Qué te costaba tomar un taxi?

Todas estábamos aturdidas. Nunca habíamos visto a An perder los estribos. Ella hablaba suavemente y siempre pensaba en los demás. Nadie dijo nada y nos limitamos a mirar a An Changhe. Años más tarde aún recordaba aquel hecho. An Changhe se arrodilló repentinamente. Se arrodilló tan abruptamente como si un par de manos invisibles hubieran golpeado su cintura delgada. Se hincó ante la cama de An, enterró su cabeza en medio de sus piernas y sollozando se quejó:

-¡Mamá! ¡Soy un inútil! ¡No la dejé vivir en paz y siempre le di muchos problemas! -y luego, abofeteándose la cara-: ¡Soy un desastre! ¡Soy una cosa inútil!

-iCCómo es que me casé con aquel patán inmortal!? ¿¡A quién le echo la culpa!? ¡A los hijos de las ranas jamás les salen pelos!

No supimos cuándo entró Elefanta Salvaje. Con la boca abierta primero miró a An y luego a su hijo. Se arrastró con sus gruesas piernas y con una mano agarró el cuello de la camisa del hijo, lentamente lo levantó, le acomodó el pelo y, mirando a la hermana An, preguntó:

$-¿ Y$ acaso el padre tiene la culpa?

- ¿Y quién es el culpable entonces?

-Tú eres la culpable.

- ¿Y por qué yo? ¡Trabajé en la fábrica de alfombras durante treinta años, y cada año recibía premios, incluso fui trabajadora modelo en la ciudad!

Elefanta Salvaje nos recorrió con la mirada: por qué.

- iClaro que tú tienes la culpa!, tócate la cabeza y sabrás

An, dudosa, se tocó la cabeza, ah ah, sonrió, y todas reímos, pues no tenía ni un pelo en la cabeza.

-Tu hijo vino de lejos sólo para verte. ¿A quién le pones esa cara larga? -inquirió Elefanta Salvaje-. ¿Acaso crees que no sabemos que estás feliz por dentro?

An Changhe se despidió en la noche. Antes de partir, se inclinó ante nosotras y nos encargó a su madre. Fue una 
noche triste. El resplandor exterior de la puesta del sol nos pintó de rojo las mejillas. Apreté con fuerza la mano de Ningmeng hasta sentir dolor provocado por sus agudas articulaciones.

Cuando llegué a casa, le pedí que se mudara del estudio al dormitorio. Esa noche lo hicimos durante mucho tiempo. Él no besó mis pechos como de costumbre; sus manos ásperas vacilaban y luego se apartaban. Lamenté su vacilación.

Me entristeció mucho algo que pasó días más tarde.

Ningmeng invitó a algunos amigos a cenar. Todos conocían sus conversaciones por chat con aquella mujer, y presuntamente para regañarlo, repitieron más o menos el contenido delante de mí. Ningmeng colgó la cabeza en son de arrepentimiento. Él siempre tenía que decirles todo a sus amigos, como si de esa manera pudiera limpiar sus pecados. Pero pronto se embriagaron y se fueron. Salí con mi hijo a pasear y Ningmeng se quedó para lavar los platos. Estaba navegando por internet cuando regresé a casa. Al verme, sus pupilas se hincharon.

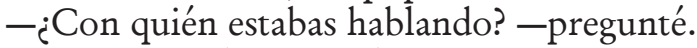

- No pasa nada, es un cliente viejo que quiere ir algún día al negocio para escoger algo de ropa-contestó.

Lo levanté de la silla.

-Ve a dormir con tu hijo -espeté furiosa-. Aquí no hay nada para ti.

Se quedó de pie inmóvil.

Efectivamente, estaba chateando con una vieja clienta. Yo la conocía; era una funcionaria del gobierno local y siempre que venía a comprar ropa en la tienda de Ningmeng, se ponía muy coqueta. Su marido, el presidente de la empresa de construcción más grande en la ciudad, jamás habría imaginado que su mujer, pequeña y recatada, era capaz de coquetear con un hombre salvaje.

- ¿Desde cuándo lo hacen? Parecen viejos amantes.

- ¿De qué estás hablando? La mujer es una dama. te mato.

- ¿Una dama? Le pediré que venga esta noche y, si viene,

Tartamudeó:

-Yo, yo, уо... 
Continué conversando con ella por el chat como si fuera Ningmeng. Le comenté que su mujer todavía estaba en quimioterapia.

-Ven esta noche -le escribí-. Preparé carne de res y podemos tomar sake japonés.

La mujer respondió rápidamente; se daría un baño y llegaría en media hora.

Apagué la computadora. Ningmeng se sentó en el balcón y fumaba muy aturdido. A la media hora el timbre sonó. Pueden imaginar la cara de la mujer cuando me vio en la puerta. Su boca estirada estaba más grande que la de un hipopótamo.

- Hermana, ¿has vuelto? Quedé con Ningmeng de recoger algo de ropa - titubeó rápidamente-. Por cierto, ¿cómo has estado?

Le sonreí y la invité a pasar a la sala. Cuando le dije que no había sido Ningmeng sino yo quien la había citado, sus ojos se aplanaron; nerviosa, se sentó en el sofá y comenzó a jalar un hilo de sus medias.

-No necesitas explicar nada, lo sé todo. La culpable es mi enfermedad, tantos gastos y preocupaciones, era inevitable que él sufriera. Afortunadamente te tuvo a ti estos días para liberar un poco de presión. Mira, mi pelo se ha ido, me acechó la mala suerte, pero no culpo a nadie.

Sollozando, indicó que entre ellos no había nada, pero que, a pesar de todo, se sentía avergonzada; prometió que jamás volvería a buscar a Ningmeng. Me pidió que no se lo dijera a su marido; suavemente me abrazó y comenzó a llorar.

-No te preocupes - respondí mientras le ofrecía una toalla húmeda- Límpiate las lágrimas. Las pestañas postizas casi se te caen en el frutero.

Elefanta Salvaje preguntó:

- ¿Por qué no te acompañó Ningmeng?

Le dije que su abuelo estaba enfermo y Ningmeng estaba con él. 
Elefanta Salvaje siguió:

- ¿Por qué bajaste de peso otra vez? Tu carita es apenas del tamaño de un puño. Tengo que darte un buen tónico.

An esta vez no regresó; dijeron que su condición había empeorado y la habían transferido al hospital de Beijing. Le marcamos por teléfono y nos apresuramos a hablar con ella. $\mathrm{Su}$ voz era la de siempre, débil y suave. Comentó que allí el ambiente era bueno, y que al salir iría a vernos. Especialmente se encargó de pedirle a Cuicui tener piedad de su marido Pies Apestosos, y le pidió a la Concubina ver menos series. Cuicui aún agobiaba al pobre Pies Apestosos; si al marido lo consideramos un caballo, entonces Cuicui era una mosca de la fruta que se le había pegado a la cola. La Concubina vio por quinta vez la serie Las emperatrices del palacio. Cambió de peluca, adornada esta vez con rosas rosadas.

$-i$ No es hermosa? - preguntó mientras retorcía los pétalos de seda-. Esa bruja emperatriz, ¿cómo puede ser tan hermosa?

Ningmeng llegó dos días después. Ni siquiera lo miré. Me compró kiwis, mi fruta preferida, peló uno con sumo cuidado y me lo ofreció. No lo tomé y él se lo comió. Su silencio me perturbó. Después de la comida, dijo que iba a salir un rato; ni siquiera le contesté. En ese momento entró Elefanta Salvaje, empapada en sudor; al parecer, apenas había terminado de limpiar los baños.

-Elefanta, ¿tienes tiempo? -le pregunté.

- Apenas terminé mi quehacer, estoy cansada.

La mandé bajar las escaleras y, desde la ventana, le pedí cruzar el estacionamiento y salir por la puerta del hospital. Pronto supe que Elefanta Salvaje no servía para ser detective, pues no mostró ningún entusiasmo. La vi regresar con los pechos muy erguidos. De pronto, meneando la cintura y torciendo las nalgas, comenzó hacer gimnasia en el estacionamiento. Sus movimientos llamaban mucho la atención; además de los movimientos acostumbrados, incorporó otros muy curiosos, por ejemplo, elevar las piernas - si han visto un espectáculo de elefantes, entonces les puedo decir que ella se movía incluso con más lentitud y elegancia que un elefante; parecía una tortuga agitando mecánicamente los brazos gordos y estirando el cuello mientras sus piernas enormes se doblaban al dar un paso-. 
Muy pronto la rodearon varios pacientes, que la señalaban con la mano mientras reían. Entonces, ella se acomodó la blusa para taparse el ombligo descubierto y lentamente caminó hacia la entrada. Cuando la vi, me jaló misteriosamente a la esquina y masculló:

-Lo seguí dos cuadras.

-¿Qué estaba haciendo?

-Este tonto compró salchichas de jamón y cerveza y se sentó a beber muy a gusto.

Yo asentía con la cabeza cuando ella preguntó:

- ¿Por qué le tienes desconfianza a Ningmeng?

Ningmeng regresó por la tarde. Sin dar ninguna explicación, le dio un cigarrillo a Pies Apestosos y juntos se fueron a fumar al balcón.

Estaban todos dormidos, mientras yo miraba el techo con los ojos bien abiertos. No había nada excepto algunas grietas torcidas en forma de rosa. Antes allí solía ver la silueta de una persona legendaria y omnipotente, acurrucada en los brazos de María y extendiendo sus labios codiciosos hacia los blancos pechos. Ahora no pude ver nada. Miré a Ningmeng durmiendo plácidamente en la cama; su respiración era uniforme. $\mathrm{Me}$ arrastré para taparlo con una manta cuando alguien me pegó en el hombro. Era Elefanta Salvaje.

-Sal conmigo -dijo susurrando.

Sorprendida, salí con ella de la habitación. En el pasillo por la noche no había nadie, pero sabía que muchos fantasmas vagaban por allí; eran almas tristes. Se detuvo delante de la báscula electrónica en la oficina de los médicos.

- Mira bien lo que peso -indicó moviendo sus gruesos párpados-. Voy a hacer magia.

-No soy miope -contesté-. Guau, ciento cinco kilos.

-Después de dos minutos, mira de nuevo cuánto peso.

El doctor de guardia estaba acostado sobre la mesa durmiendo, y el tiempo en el reloj de la pared estaba corriendo. Elefanta Salvaje tosió un poco y eché otro vistazo a la báscula: ciento dos punto cinco kilos. Incrédula, la miré a ella y luego miré la báscula:

-¿Qué demonios estás haciendo? 
-No hago trucos. Éste es mi secreto -expresó misteriosamente-. De niña accidentalmente lo descubrí.

La ayudé a bajar de la báscula mientras ella preguntó: del alma.

- ¿Sabes dónde están los dos kilos y medio? Ése es el peso

Me reí. Ella movió sus enormes fosas nasales y explicó:

-Es cierto, cuando no piensas en nada, el alma sale del cuerpo y tu peso disminuye dos kilos y medio.

-Tonterías - repliqué-; en la televisión dicen que el alma pesa veintiún gramos.

-Dos kilos y medio o veintiún gramos, da igual, lo importante es que hay algo más que esta carne.

-Eso es cierto - asentí mirándola extrañada.

- Tal vez esa parte es la más importante. La carne se muere, la queman, se convierte en ceniza, pero el alma se queda. Tal vez permanece en el cementerio, o tal vez flota por ahí con el viento. ¿Sabes? Cuando mueren los amargados, su alma tiene cara larga todo el día y se esconde del mundo; el alma de los alegres, en cambio, es alegre incluso cuando sus dueños se mueren; baila, charla con los gorriones posados en los alambres de electricidad, se divierte en la pradera con los ratones de campo $y$, en el lomo de un caballo, discute con las pulgas quién será el próximo presidente de Estados Unidos.

Me reí. Ahora ese cuerpo enorme, envuelto en un halo, ya no era el de una mujer grotesca que peleaba y regateaba por botellas vacías, era la silueta de un predicador solemne. Sus ojos brillantes parecían tener una pequeña llama ardiendo en la pupila.

-No juntes las cejas caídas durante todo el día como si alguien te debiera quinientos pelos. Tienes suerte; aunque fue cáncer de mama, se atendió a tiempo. Pobre An, su tumor era benigno y quién sabe cómo las células se tornaron malignas - dijo.

Miré fijamente sus ojos pesados y grises sin saber qué decir. Sabía que había querido contentarme. Pero ¿cómo podía estar contenta?

-Estoy bien, estoy bien - repuse dejando caer un párpado-. Tal vez es una resaca de la quimioterapia que no me deja estar en paz. 
-Qué bueno que ya entiendes - respondió mientras se lamía los gruesos labios-, pero debo corregirte, el alma no pesa veintiún gramos sino dos kilos y medio.

- Bueno - le sonreí-; pesas más que yo, así que tu alma también pesa más que la mía.

Cuando regresé al cuarto, Ningmeng estaba susurrando en el teléfono.

$-¿$ Con quién estás hablando? Es demasiado tarde para acosar a la gente.

Me miró tímidamente y a toda prisa colgó.

-Muéstramelo -le ordené señalando el móvil.

Dudó un momento. Caminé hacia él e intenté quitárselo. Se quedó pasmado por un momento, y luego, murmurando algo, me empujó. Jamás pensé que sería capaz de hacer eso. Desesperado, brincó el cuerpo dormido de Pies Apestosos y se abalanzó hacia mí. Le arrebaté el teléfono de la mano y lo tiré contra la pared.

El ruido fue grande. La Concubina despertó y, tocándose la cabeza, preguntó asustada:

-¡Madre mía!, ¿explotó el cilindro de oxígeno o es un terremoto?

Ningmeng inclinó la cabeza y salió del cuarto. No regresó. Si se congela en la calle, que se congele, pensé.

\section{7}

Al día siguiente, al mediodía, la Concubina aún me regañaba: -Ustedes los jóvenes por cualquier cosa se encienden, ¿crees que él la tiene fácil? En la casa cuida al hijo; en el hospital, a ti. ¿No puedes ahorrarle algunos problemas?

Elefanta Salvaje me trajo un plato de algas marinas en salsa de ajo, dijo que en el camino se había tirado mucho aceite de sésamo, pero ni modo. Luego preguntó:

-Por la noche... ¿ ¿puedo invitarte a un espectáculo?

- ¿Qué espectáculo?

Ella vaciló. No pude evitar reírme de su timidez. Con los ojos encendidos, celebró: 
-Ya aceptaste, ¿eh? ¡Genial! Te esperaré en la puerta del hospital a las siete y media. Te pones guapa.

No me vestí bien, la que se puso muy guapa fue la Concubina. Llevaba un $q i p a o^{4}$ precioso. Estaba un poco arrugado, por lo que, de pie con aquel viento de otoño, no podía resistir ponerse saliva en las uñas y estirar la tela sin parar. Lo más sorprendente eran sus pechos altos y suaves, pero no tuve valor de preguntar.

- ¿Crees que nos va a llevar a la ópera? En la radio escuché que en el teatro Yanshan esta noche se presenta la orquesta de Montenegro con El barbero de Sevilla...

Pero de inmediato reviró:

-Elefanta Salvaje es muy ordinaria; se pone tanto lápiz labial que hasta raspa los labios, lo más probable es que nos lleve a ver algún diálogo corriente, pues, desafortunadamente, ella no tiene estilo ni clase, es una simple afanadora.

Cuicui también quería ir, con Pies Apestosos, pero después de que la Concubina le susurró algo al oído, decidió quedarse. Cuando vio a la Concubina, Elefanta Salvaje se sorprendió, pero no dijo nada. La Concubina, exagerando el tono de reproche, previno:

-Si nos llevas a ver algún diálogo aburrido, me habré puesto el qipao en vano.

Elefanta Salvaje, aturdida, la miró de reojo y apuntó:

-Es la primera vez que veo a alguien ir con qipao a una discoteca.

Para ser sincera, no esperaba que Elefanta Salvaje nos llevara a una discoteca. En toda mi vida apenas había ido unas cuantas veces, y seguramente la Concubina también. Cuando el guardia de seguridad inspeccionaba nuestros bolsos y nos ponía sellos en la muñeca, ocurrió un incidente. La Concubina se negó a dejarle al guardia de seguridad su vieja navaja del ejército suizo. Elefanta Salvaje y yo tuvimos que apartarla, y entonces ella explicó:

-Esta navaja me la dio mi exmarido, siempre la tengo conmigo. ¿Qué pasa si el guardia la pierde? -frunció la boca y siguió-. O si le gusta, se la queda y ya.

\footnotetext{
${ }^{4}$ Vestido típico chino.
} 
Elefanta Salvaje y yo intentamos persuadirla durante un largo tiempo y, finalmente, accedió a dejar la navaja, pero obligó al guardia a entregarle una nota de depósito.

Adentro había mucha gente. Elefanta Salvaje encontró dos asientos para nosotras, ordenó bebidas y sigilosamente desapareció. La Concubina, sentada en un taburete alto, cada tanto estiraba las mangas del qipao. Nadie sospechó que allí había dos mujeres sin senos.

-Es demasiado ruidoso - se quejó la Concubina-, hay más ruido que en un simulacro de temblor escolar. ¿Quiénes son estas personas?

-Gente como nosotras.

-Sabía que esta estúpida mujer no nos llevaría a ningún lugar bueno.

-A mí me gusta el lugar.

-Claro que no, aquí hay pura chusma.

Elefanta Salvaje aún no regresaba. La Concubina y yo, aturdidas, veíamos a la gente bailar sin poder distinguir a los hombres de las mujeres.

$-¿$ QQuieres tomar una cerveza? - preguntó-. Yo antes podía con medio litro de Laobaigan. ${ }^{5}$

- Aquí la bebida es muy cara - contesté.

Ella me miró con desdén:

-Mírate, qué tacaña.

Bebimos cerveza. Hacía mucho tiempo que no tomaba. Recordé que cuando me aburría, tomábamos vino con Ningmeng en casa. Jamás pudo conmigo. Pensar en él me había quitado las ganas de beber.

- ¿Están bonitos mis senos? - pregunto la Concubina China riendo-. ¿Son sexis?

-No tenía el coraje de preguntar, pero ¿qué llevas puesto?

-No sabes, ¿verdad? El mantou ${ }^{6}$ del comedor es suave, grande y esponjado.

Estábamos allí charlando, cuando las luces se atenuaron y la multitud se calmó. El reflector y la música se centraron en un tubo de acero. Por poco se nos cae la mandíbula al ver que, al lado del tubo, estaba una mujer muy gorda. Tenía un pelo

${ }^{5}$ Marca de licor chino.

${ }^{6}$ Panecillos al vapor. 
castaño muy inflado, una ancha boca escarlata y unos brazos dignos de un activo marinero. Envuelta en un velo repleto de incrustaciones brillantes, de pie allí, se veía como una glamorosa criada filipina.

-Ella... ¿es Elefanta Salvaje? -la espuma de la cerveza corrió por los labios de la Concubina- ¿Está loca?

- Sí, es ella -confirmé acariciándome el pecho-. Será mejor que nos escondamos por allí en caso de que se caiga del escenario.

Pero no nos cambiamos de lugar. Miramos a Elefanta Salvaje torcer sus caderas gigantes al son de la música, la vimos parpadear con mirada graciosa abrazando el tubo brillante, sacudir los senos, levantar sus piernas de elefante. Seguramente creía que aún era una niña de siete u ocho años haciendo un salto de lobo o un salto mortal en la barra de equilibrio. Cuando la miré luchar para aferrarse al tubo de acero con la pierna izquierda en posición vertical y la derecha formando un ángulo de noventa grados con el tubo, sentí el corazón a punto de estallar.

- ¡Genial! - gritó la Concubina- ¡Arriba Elefanta Salvaje!, ¡nadie como tú!

Me esforcé para gritar, pero nuestras voces se perdieron entre los silbidos, los aplausos y los gritos histéricos. Si bien recuerdo, su último movimiento fue sostener los pechos con las manos y estirar las piernas en un ángulo de ciento ochenta grados. Nunca entendí por qué tuvo que sostener sus senos en lugar de cubrirse las gruesas rodillas con las manos y así darle más soporte a su cuerpo. Cuando, ruborizada, se puso de pie, vi que su falda estaba desgarrada. Mientras caminaba lentamente para bajar del escenario, alguien se acercó para tocar su muslo desnudo. A ella no le importó; bajo las luces de neón, atravesando la multitud, caminó hacia nosotras.

-Cuatrocientos yuanes la noche.

Elefanta Salvaje, orgullosa, bebió cerveza:

-Soy la bailarina más popular aquí.

La Concubina China y yo asentimos al unísono.

- ¿Feliz, mujer hermosa? -sus fosas nasales aún sacaban aire caliente-. El jefe de la discoteca me rogó tres veces antes de aceptar. 
Le ofrecí un vaso grande de Heineken. Estaba contenta y triste a la vez. De repente recordé el alma de la que ella me había hablado, aquella que vaga al son del viento salvaje, aquella que en el lomo de un caballo charla con las pulgas y quizá pesa dos kilos y medio.

\section{8}

En cuanto a la experiencia de la discoteca, la Concubina China y yo guardamos silencio. Cuicui se moría de ganas por saber qué espectáculo tan maravilloso habíamos visto. Finalmente, la Concubina, apretando la boca, comentó:

- ¡Qué aburrido! Era un diálogo, medio encendido, que montaron los discípulos de Zhao Benshan. ${ }^{7}$

Cuando vi de nuevo a Elefanta Salvaje, me sonrió tímidamente. Levanté el pulgar son de aprobación, y ella, con la boca fruncida, me estrujó la mano y dijo:

-Recuerde dar propina la próxima vez.

Cuando estaba sola comenzaba a pensar en Ningmeng. Mi madre me llamó por teléfono y me preguntó:

- ¿Por qué mandaste a Ningmeng a casa? ¿Puede uno estar solo en un hospital? ¿Por qué no voy esta tarde?

Le dije que no era necesario, que estaba bien acompañada y que era mejor que Ningmeng cuidara a su hijo en su casa. Además, era mi última quimioterapia y en dos días regresaría. Mamá suspiró y no agregó nada más.

El médico comentó que me había recuperado muy bien, y que sólo tenía que cuidarme y revisarme periódicamente. La Concubina también se alistaba para regresar a su ciudad. $\mathrm{Mu}-$ chos días llevó puesto aquel qipao antes de quitárselo. Cuicui era la más feliz; la cosecha de castañas ese año había sido muy buena, por lo que nos invitó a visitarla en la montaña la siguiente primavera para ver la flor del castaño, cuya deliciosa fragancia se podía percibir a kilómetros. Acordamos visitarnos en el futuro; después de todo, el hospital nos había unido, juntas habíamos soportado la misma desgracia. Pero yo sabía que

${ }^{7}$ Artista de obras en diálogo, populares en China. 
ésos sólo eran buenos deseos. Justo ese día leí en una entrevista a un director de cine de Hong Kong que siempre llevaba gafas de sol: "A menudo nos encontramos con algunas personas que aparecen en nuestras vidas en cierto tiempo y espacio, que nos marcan y luego desaparecen para siempre". Tenía razón.

La noche antes de que me dieran de alta, Elefanta Salvaje me invitó a comer el bistec prometido. Conocía ese restaurante de comida rápida, bueno y barato. Después de esperarla sentada un buen rato, vi a Elefanta Salvaje entrar jadeando al restaurante. Para mi sorpresa, iba empujando a un niño en silla de ruedas. El niño me saludó desde lejos.

-Dile tía - le indicó Elefanta Salvaje-. La tía es la bodhisattva del hospital.

El niño torció la cabeza para sonreír, y de la comisura de la boca de vez en cuando le escurría saliva. Elefanta Salvaje sacó su pañuelo, lo limpió rápidamente, y luego se sentó enfrente de mí.

$-¿$ De quién es este niño? -no pude evitar preguntar-: ¿Cuál es su enfermedad?

Elefanta Salvaje parecía no oír, y con sus enormes pechos sobre la mesa ordenaba la comida. Cuando el mesero se fue, susurró:

-El parto difícil le lesionó el cerebro, es parálisis cerebral. Es muy inteligente, sólo que no puede caminar -y luego agregó, dirigiéndose a él-: Cariño, recítale a la tía un poema de la dinastía Tang.

El niño levantó la barbilla, puso su pequeña mano detrás de su espalda, y comenzó a recitar Pensamientos en la noche silenciosa. ${ }^{8}$ Probablemente lo había recitado muchas veces. Al terminar, se agachó y me miró fijamente mientras Elefanta Salvaje le ponía un dulce en la mano.

${ }_{-}$¿Es hijo de algún familiar?

-No -dijo mirándome fijamente-, es mi hijo.

No supe qué decir. Yo sabía que no estaba casada y no pude resistir:

-El niño... ¿y el padre?

Sus ojos pardos se oscurecieron aún más.

${ }^{8}$ Poema del famoso Li bai, de la dinastía Tang, 
-Él no tiene padre -con los dientes mordisqueaba sus labios gruesos una y otra vez-. Él no tiene padre -repitió.

Sólo dijo eso y se puso a limpiar la saliva del niño. Pensé mucho tiempo y después confesé:

- Te conozco desde hace tanto tiempo y sólo te he llamado Elefanta Salvaje, ¿cuál es tu nombre?

${ }_{-}$Ey! -sonrió y explicó-: $\mathrm{Mi}$ apellido es $\mathrm{Lu}$, mi nombre es Yexiang, que significa fragancia. Me puedes llamar Yexiang -agregó tímidamente-, y como no estoy casada, puedes decirme señorita Fragancia.

El niño podía comer solo. Usó el cuchillo y el tenedor para cortar el bistec metódicamente, como si fuera un cocinero habilidoso.

-A menudo lo traigo - suspiró Elefanta Salvaje-. He tragado muchas penas por este niño...

Fue una cena inolvidable. Elefanta Salvaje y su hijo ordenaron un total de cuatro platos de bistec término tres cuartos, dos porciones de pizza de frutas y seis helados. Quería pedir una botella de vino, pero le dije que yo no quería y no insistió. El apetito de su hijo no era pequeño; ella ocasionalmente acariciaba su pelo fino, como una elefanta madre, un poco cansada, que acaricia a su débil elefantito que sólo puede estar sentado. Los ojos de ambos eran muy parecidos, pero las pupilas del niño brillaban más.

Ésa fue la última vez que vi a Elefanta Salvaje. Cuando Ningmeng vino al hospital a recogerme, ella aún no llegaba. Era otoño, y me puse a lavar cobijas y edredones para secarlos al sol de la terraza. Me habló la Concubina para decirme que ya había regresado a trabajar, pues si no veía pronto a sus estudiantes, entraría en una depresión. Llegó el invierno y recibí una llamada de An Changhe. Tartamudeando y de prisa, anunció que An había fallecido, pero que antes de morir había dejado un regalo para cada una de nosotras, dijo que en esos días nos visitaría para entregárnoslos. Con el teléfono en la mano, no pronuncié ni una palabra y me puse a llorar; hacía tiempo que no derramaba tantas lágrimas.

Ningmeng y yo estábamos igual; podíamos pasar días sin hablar. Comenzó a tomar algunos pedidos y a tallar budas para clientes, o manubrios de ébano para los amigos del club de mo- 
tos. Aunque el pago no era mucho, era mejor que nada. Una noche se cortó la mano izquierda y la sangre comenzó a brotar por todos lados. Me apresuré a encontrar polvo de Yunnan ${ }^{9}$ y le vendé la mano. Cuando le sujeté la última parte de la venda, abrazó mi cintura con el brazo derecho y jadeando me llevó al sofá. Su fuerza, aún muy grande, me mareó... Cuando sus labios osaron besar mi pecho plano, sólo acaricié su pelo corto. La luz seguía encendida y miré fijamente el tejado. De nuevo vi a aquel hombre omnipotente; era todavía un niño, acurrucado en los brazos de María, con un rostro lleno de ansiedad.

Cuando Ningmeng se durmió, tomé una ducha y me senté en el sofá a ver la televisión. Rara vez veía la televisión y ese día me quedé viendo el canal publicitario de la ciudad. Repetían una y otra vez un anuncio sobre la gota. Una mujer grande y gorda miraba la cámara y decía:

-Tengo gota desde hace tres años, las dos rodillas, tiesas e hinchadas, me duelen; no puedo sentarme ni levantarme. Para bajar o subir escaleras debo inclinarme y cada mes debo medicarme. Conforme la enfermedad se fue agravando, el médico sugirió remplazo de la articulación. Estaba total y absolutamente desesperada, cuando, accidentalmente, mi marido, en una reunión en Taiwán, a través de un camarada, conoció las cápsulas de hormiga para la gota...

Lo único que tenías que hacer para curarte era tomar las cápsulas. Para verificar el efecto médico, la conductora invitó a una cantante del Noreste. Sus extremidades eran enormes y abultadas; en el escenario, al son de la música, parecía un elefante que no dejaba de sonreír mientras aleteaba.

A decir verdad, fue la sonrisa más conmovedora que jamás había visto en mi larga vida, simple y trivial.

${ }^{9}$ Remedio conocido en la medicina tradicional china. 
